07

\title{
Спин-туннельные магниторезистивные элементы на основе многослойных наноструктур
}

\author{
() В.В. Амеличев, ${ }_{1}^{1}$ П.А. Беляков, ${ }^{1}$ Д.В. Васильев, ${ }^{1}$ Д.А. Жуков, ${ }_{1}^{1}$ Ю.В. Казаков, ${ }^{1}$ Д.В. Костюк, ${ }^{1}$ \\ Е.П. Орлов, ${ }^{1}$ С.И. Касаткин, ${ }^{2}$ А.И. Крикунов ${ }^{3}$ \\ ${ }^{1}$ Научно-производственный комплекс „Технологический центр“ МИЭТ, \\ 124498 Зеленоград, Россия \\ ${ }^{2}$ Институт проблем управления им. В.А. Трапезникова РАН, \\ 117997 Москва, Россия \\ ${ }^{3}$ ООО НПК „Фотрон-Авто“, \\ 117105 Москва, Россия \\ e-mail: goodnessgims@mail.ru
}

(Поступило в Редакцию 29 ноября 2016 г.)

\begin{abstract}
Представлены результаты исследования характеристик спин-туннельных магниторезистивных (СТMР) элементов, сформированных на основе многослойных наноструктур масочным методом. Экспериментально получены параметры магнитного отжига СТМР элементов, которые показывают возможности повышения величины магниторезистивного эффекта в 4-5 раз и более. Исследованы тестовые образцы СТМР элементов, обладающие величиной гигантского магниторезистивного эффекта до $50 \%$ и сопротивлением $30-35 \mathrm{k} \Omega$, в отсутствие магнитного поля.
\end{abstract}

DOI: $10.21883 /$ JTF.2017.08.44740.2116

В настоящее время спинтронные приборы и устройства на основе спин-туннельных магниторезистивных (СТМР) элементов востребованы в ряде приложений. Величина гигантского магниторезистивного (ГМР) эффекта в таких элементах достигает нескольких сотен процентов. Это позволяет не только контролировать слабые значения магнитного поля в диапазоне от $1 \mathrm{nT}$ до $1 \mathrm{mT}$, но и хранить информацию в устройствах энергонезависимой магниторезистивной памяти.

Одним из перспективных направлений магнитной спинтроники сегодня является создание высокочувствительных датчиков и преобразователей магнитного поля на основе ГМР эффекта, достигающего нескольких сотен процентов в СТМР элементах [1,2].

Сопротивление СТМР элемента на основе многослойной наноструктуры изменяется пропорционально косинусу разности между углами направлений векторов намагниченности М свободной и фиксированной ферромагнитных пленок. При этом сопротивление СТМР элемента максимально при противоположном направлении векторов М и минимально при их сонаправленном, параллельном положении векторов М ферромагнитных пленок. Направление вектора намагниченности М фиксированной ферромагнитной пленки в рабочем диапазоне магнитного поля осуществляется благодаря обменному взаимодействию с прилегающей к ней антиферромагнитной пленкой из сплавов FeMn или IrMn.

Основой всех СТМР элементов является туннельный переход, расположенный между двух ферромагнитных пленок (фиксированной и свободной). Туннельный переход реализуется в многослойной наноструктуре СТМР элемента с помощью нанометрового слоя диэлектрика $\mathrm{Al}_{2} \mathrm{O}_{3}$ или $\mathrm{MgO}$. Протекание „магнитозависимого“ тока в туннельном переходе происходит перпендикулярно слоям многослойной наноструктуры СТМР элемента. Перемагничивание свободного ферромагнитного слоя происходит под воздействием магнитного поля, направленного параллельно поверхности многослойной наноструктуры СТМР элемента. Для этого в первую очередь в запоминающих устройствах с произвольной выборкой (ЗУПВ) используются токовые проводники перезаписи [3]. При переходе к созданию наноразмерных СТМР элементов стало возможно использование квантового явления переноса спинового момента, позволяющего перемагничивать свободный ферромагнитный слой благодаря проходящему через многослойную наноструктуру „магнитозависимого“ тока с плотностью до $10^{7} \mathrm{~A} / \mathrm{cm}^{2}[4,5]$.

Теоретический анализ работоспособности СТМР элемента в магнитном поле может быть проведен с использованием теории микромагнетизма [2]. В качестве модели распределения магнитного момента М ферромагнитных свободной и фиксированной пленок для упрощения вычислений берется его однородное распределение по всему объему пленки. Применение такой приближенной модели, которая не учитывает поворот М у краев пленки, обеспечивает приемлемую для дальнейшего применения точность. Расчет вольт-эрстедной характеристики (ВЭХ) $V(H)$ СТМР элемента может быть проведен следующим образом. Вначале на основе микромагнитной теории определяются зависимости направлений М ферромагнитных пленок с различными полями перемагничивания от внешних и внутренних магнитных полей, создаваемых в СТМР элементе. Затем на основе полученных результатов и способов питания СТМР элемента определяется его ВЭХ. 


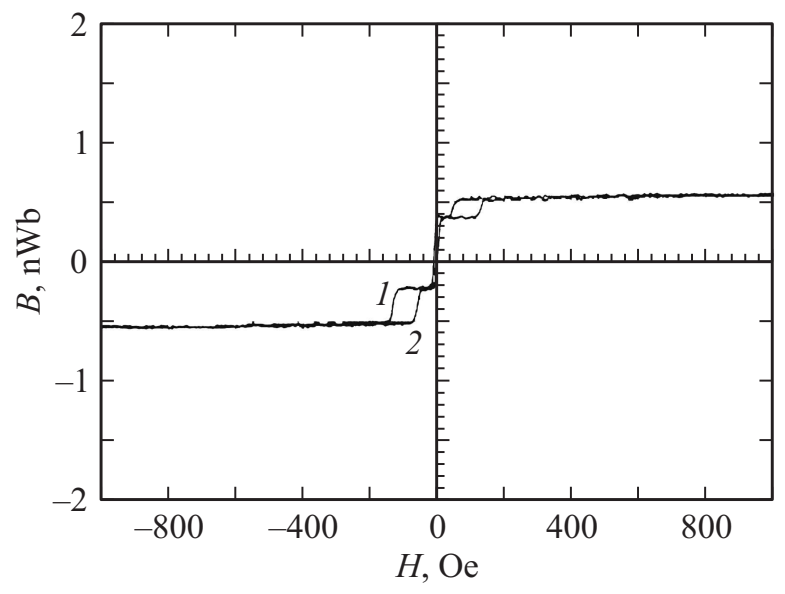

Pис. 1. Петля гистерезиса типичной СТМР наноструктуры, где 1 - прямой, а 2 - обратный ходы.

В результате экспериментальных исследований технологического процесса изготовления СТМР элементов были получены петли гистерезиса наноструктур с различными комбинациями пленок в их составе и режимы температурного воздействия, позволяющие многократно повышать ГМР эффект. Технологический процесс формирования СТМР элементов производился без применения процессов фотолитографии и травления, с использованием трафаретов и установки магнетронного напыления, оснащенной пятью мишенями. На заключительном этапе изготовления многослойной наноструктуры к магниторезистивным полоскам свободной и фиксированной пленок формировались области контактных площадок. Для ускорения создания СТМР элементов и исследования их электромагнитных характеристик, при оптимизации технологического процесса напыления наноструктур, могут быть использованы специализированные трафареты. Это позволяет минимизировать время получения тестовых наноструктур при оптимизации толщины функциональных слоев.

На кремниевые пластины диаметром 100 mm, содержащие термический оксид кремния, последовательно из пяти мишеней напылялись слои пленок $\mathrm{Ta}-\mathrm{FeNiCo}-$ CoFeB-MgO-CoFeB-FeNiCo-FeMn-Ta. Ha рис. 1 приведена петля гистерезиса $B(H)$ большого числа СТМР полосок размером до нескольких десятков микрон, измеренная на индукционной установке MESA-200 в переменном магнитном поле, направленном вдоль оси легкой намагниченности (ОЛН) ферромагнитных FeNiCoпленок. Петля гистерезиса сформированной наноструктуры состоит из трех петель: петли перемагничивания свободной пленки с небольшой коэрцитивной силой $H_{c}=1600 \mathrm{~A} / \mathrm{m}$ и двух сдвинутых в противоположных направлениях внешнего магнитного поля (вследствие обменного взаимодействия) на величину до $8 \cdot 10^{3} \mathrm{~A} / \mathrm{m}$ петли гистерезиса фиксированной $\mathrm{FeNiCo-пленки} \mathrm{с}$ $H_{c}=3.2 \cdot 10^{3} \mathrm{~A} / \mathrm{m}$. Полученные магнитные характеристики СТМР наноструктур позволяют создавать тонко- пленочные магниточувствительные элементы с требуемыми электромагнитными параметрами.

В результате исследования изменения сопротивления $R(H)$ сформированного СТМР перехода при комнатной температуре на специализированном стенде, позволяющем задавать магнитное поле, направленное вдоль ОЛН ферромагнитных пленок, было установлено, что его сопротивление изменяется в диапазоне $1.85-2.05 \mathrm{k} \Omega$ (рис. 2). Это изменение сопротивления СТМР наноструктуры характеризуется относительно небольшим значением СТМР эффекта на уровне 9-10\%.

Известно, что для повышения величины магниторезистивного (МР) эффекта СТМР наноструктур используется отжиг в магнитном поле [6-9]. Для определения оптимальных параметров магнитного отжига данной СТМР наноструктуры был создан специализированный стенд, обеспечивающий в немагнитной камере вакуум $10^{-2} \mathrm{~Pa}$, нагрев до $400^{\circ} \mathrm{C}$ и магнитное поле напряженностью до $24 \cdot 10^{3} \mathrm{~A} / \mathrm{m}$. После проведения оп-

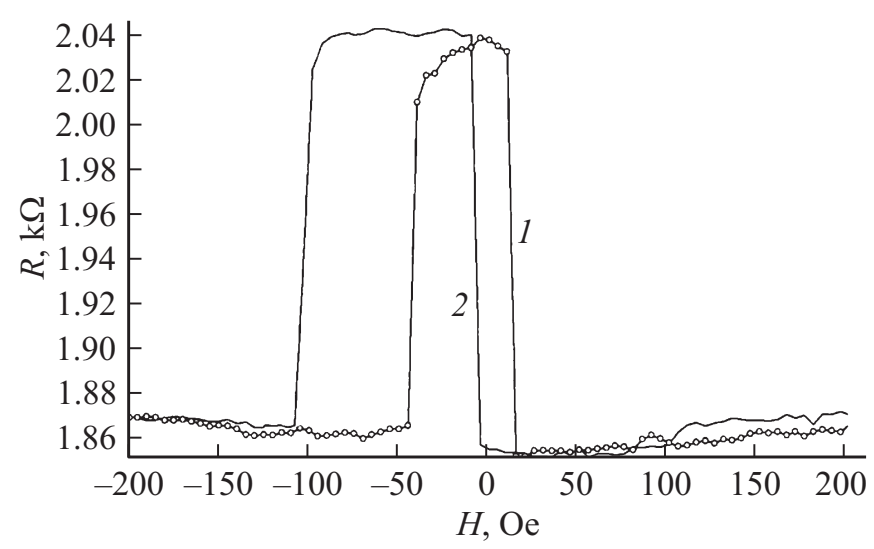

Рис. 2. Зависимость сопротивления экспериментального СТМР перехода от изменения магнитного поля от -200 до $+200 \mathrm{Oe}$, определенная до магнитного отжига, где 1 прямой, а 2 - обратный ходы.

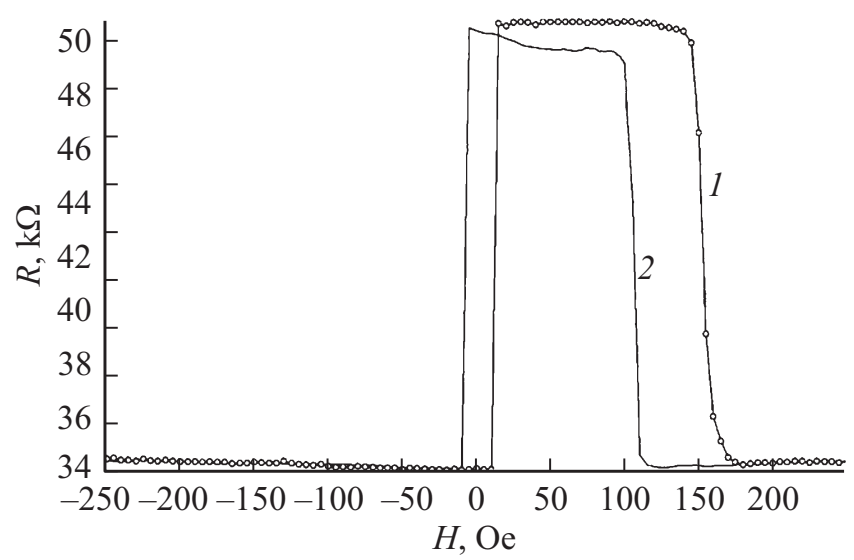

Рис. 3. Зависимость сопротивления экспериментального СТМР перехода от изменения магнитного поля от -200 до $+200 \mathrm{Oe}$, определенная после магнитного отжига, где 1 прямой, а 2 - обратный ходы. 
тимального режима магнитного отжига в зависимости от сопротивления $R(H)$ СТМР перехода произошли следующие изменения: увеличилось начальное сопротивление до $35 \mathrm{k} \Omega$ и увеличился ГМР эффект до $50 \%$ (рис. 3). Измерения наноструктур осуществлялись при комнатной температуре. Температура отжига СТМР наноструктуры с антиферромагнитным слоем на основе сплава FeMn ограничена величиной $230^{\circ} \mathrm{C}$. Его замена на слой из сплавов IrMn, PtMn позволит проводить технологический процесс магнитного отжига в более высоких температурах до $500^{\circ} \mathrm{C}$ и, как следствие, это позволит повысить величину ГМР эффекта до нескольких сотен процентов [9].

Таким образом, рассмотренные в настоящей работе результаты исследования СТМР элементов с ГМР эффектом до $50 \%$ могут способствовать разработке серийных технологий изготовления перспективных отечественных высокочувствительных МР преобразователей магнитного поля и ряда других приборов с характеристиками, соответствующими мировому уровню. Настоящая работа выполнена при финансовой поддержке Минобрнауки России в рамках Государственного заказа на 2014-2015 гг. Исследование параметров напыляемых наноструктур осуществлялось с помощью уникального оборудования ЦКП „Функциональный контроль и диагностика микро- и наносистемной техники“ на базе НПК „Технологический центр“.

\section{Список литературы}

[1] Ферт А. // УФН. 2008. Т. 178. № 12. С. 1336-1348.

[2] Касаткин С.И., Васильева Н.П., Муравьёв А.М. Спинтронные магниторезистивные элементы и приборы на их основе. М.: Электронинформ, 2005. 168 с.

[3] Prejbeanu I.L., Kerekes M., Sousa R.C., Sibuet H. et al. // J. Phys.: Condens. Mater. 2007. Vol. 19. P. 1-23.

[4] Гуляев Ю.В., Зильберман П.Е., Панас А.И., Эпитейн Э.М. // УФН. 2009. Т. 179. № 4. С. 359-368.

[5] Касаткин С.И., Муравьёв А.М., Васильева Н.П. // Датчики и системы. 2014. № 1. С. 55-59.

[6] Park C., Zhu J.-G., Moneck M.T., Peng Y., Laughlin D.E. // J. Appl. Phys. 2006. N 99.

[7] Lu Y., Lépine B., Jézéquel G., Ababou S., Alnot M., Lambert J., Renard A., Mullet M., Deranlot C., Jaffrés H., Petroff F., George J.-M. // J. Appl. Phys. 2010. N 108.

[8] Абанин И.Е., Амеличев В.В., Беляков П.А., Васильев Д.В., Казаков Ю.В., Костюк Д.В., Крикунов А.И., Орлов Е.П. // Нано- и микросистемная техника. № 4. 2015. С. 10-14.

[9] Wang W.G., Ni C., Miao G.X., Weiland C., Shah L.R., Fan X., Parson P., Jordan J., Kou X.M., Zhang Y.P., Stearrett R., Nowak E.R., Opila R., Moodera J.S., Xiao J.Q. // Phys. Rev. 2010. N 81. 